\title{
Anomie and the Moral Regulation of Reality: The Durkheimian Tradition in Modern Relief
}

\author{
Richard A. Hilbert \\ Sociological Theory, Vol. 4, No. 1. (Spring, 1986), pp. 1-19.
}

Stable URL:

http://links.jstor.org/sici?sici=0735-2751\%28198621\%294\%3A1\%3C1\%3AAATMRO\%3E2.0.CO\%3B2-N

Sociological Theory is currently published by American Sociological Association.

Your use of the JSTOR archive indicates your acceptance of JSTOR's Terms and Conditions of Use, available at http://www.jstor.org/about/terms.html. JSTOR's Terms and Conditions of Use provides, in part, that unless you have obtained prior permission, you may not download an entire issue of a journal or multiple copies of articles, and you may use content in the JSTOR archive only for your personal, non-commercial use.

Please contact the publisher regarding any further use of this work. Publisher contact information may be obtained at http://www.jstor.org/journals/asa.html.

Each copy of any part of a JSTOR transmission must contain the same copyright notice that appears on the screen or printed page of such transmission.

The JSTOR Archive is a trusted digital repository providing for long-term preservation and access to leading academic journals and scholarly literature from around the world. The Archive is supported by libraries, scholarly societies, publishers, and foundations. It is an initiative of JSTOR, a not-for-profit organization with a mission to help the scholarly community take advantage of advances in technology. For more information regarding JSTOR, please contact support@ jstor.org. 


\title{
ANOMIE AND THE MORAL REGULATION OF REALITY: THE DURKHEIMIAN TRADITION IN MODERN RELIEF*
}

\author{
RichaRD A. HilberT \\ Gustavus Adolphus College
}

\begin{abstract}
Anomie is one of the few uniquely sociological concepts (Parsons 1968). Yet it continues to be shrouded in conceptual difficulty (Shoham and Grahame 1982). Doubts revolve around the identification and measurement of anomie and its status "outside" of individuals, independent of individuals, with phenomenal and behavioral consequences for individuals (Schacht 1982; Seeman 1982). Our purpose in this paper is to address this confusion by way of clarification, to locate anomie as an empirically available phenomenon, and to recover anomie theory from the classics and put it to work on behalf of recent trends in sociological theory.

We begin in the first section with a reading of Durkheim's sociology which leads us to the conclusion that anomie as moral deregulation is simultaneously the withdrawal of reality and of the possibility of objective experience. In the second section we review recent developments in sociology, specifically a broad area that hangs together loosely as reality construction theory, with special attention to ethnomethodology. We shall argue that reality withdrawal amounts to trouble in the social production of reality. In the third section we probe three empirical examples of anomie as we have formulated it and describe the consequences anomie necessarily has for the individual. Finally we conclude with a discussion of the misgivings concerning anomie theory cited above and how our reformulation addresses these misgivings.
\end{abstract}

\section{DURKHEIM'S THEORY OF ANOMIE AND SOCIAL CONSTRAINT}

As is wise with second guessing any historical figure from the vantage of contemporary developments, our view of Durkheim put forth here is presented without pretense. Certainly we are not claiming to have finally succeeded, where others have failed, in discovering the definitive meaning of his work. Indeed, excursions into an author's

* Direct all correspondence to: Richard A. Hilbert, Department of Sociology/Anthropology, Gustavus Adolphus College, St. Peter, Minnesota 56082.

An earlier version of this paper was presented at the meetings of the American Sociological Association, Washington, DC, August 1985. The author wishes to thank Randall Collins, David F. Luckenbill, Douglas W. Maynard, Melvin Seeman, R. Stephen Warner, and Norbert Wiley for their encouraging comments on previous drafts. work to reveal the "real" intent behind the author's words, i.e. that which moves beyond what the author ever said, are fraught with analytic difficulties and we would not presume to embark on such an enterprise. Rather our references to Durkheim are strategically selected, emphasizing certain strains in his sociology as opposed to others, recasting them in new light, in an attempt to reassess conventional interpretations of Durkheim vis-a-vis anomie. We maintain that strategic readings of Durkheim have produced the conventional wisdom in these areas anyway, and that this is part and parcel of the scholarly enterprise. Our interpretations, moreover, are not strictly our own; we travel well paved roads (Coser 1971; Giddens 1971; Parsons 1968; Nisbet 1974). Yet we seek to redress an imbalance in anomie theory that is largely a result of institutionalized orthodoxies with respect to Durkheim's work, and we do this by focusing on dimensions of the work that are normally understressed or otherwise not viewed together in a systematic way. Such correction will be helpful in improving our vision of anomie against a backdrop of contemporary sociological theory.

We part company with common interpretations of Durkheim with their emphasis upon: a) moral order as norms, b) anomie as normlessness, and c) anomic suicide as deviance. Instead we emphasize: a) moral order as the source of objective reality, b) anomie as the withdrawal of moral reality, and c) anomic suicide as a behavioral manifestation of anxiety precipitated by a reduction of objective experience. These highlights will be combined with material in later sections to develop a formulation of anomie that answers some of the doubts and criticisms raised about anomie theory generally.

\section{Exteriority and Constraint}

Within the lexicon of Durkheimian terminology, certainly "exteriority and constraint" are among the most famous, and with good reason. They are absolutely central to Durkheim's entire intellectual mission. They are crucial, for example, to his research methodology (Coser 1971; Giddens 1971), most notably his recommendation to view society, or social facts, as things (Durkheim 1938, p. 14). It was precisely the character of these things as external to any individual that rendered them amenable to scientific investigation as phenomena in their own right in the first place, as opposed to 
collectivities of individual or psychologistic traits (Durkheim 1938, pp. 14-46). Thus did Durkheim carry to fruition Comte's newly coined discipline, sociology, as the science of society itself (or "moral life"'), countering the reductionist fallacy not merely with organicist rhetoric but with empirical discovery.

No less crucial to Durkheim's general sociology is the recognition that social facts are things not only for scientists who study them but for each individual member of society as well (Parsons 1968 , p. 313). Members confront an objective society, something given prior to their birth that will survive each member's death. That society has a moral quality is beyond question, indeed beyond anybody's control. Its force as a controlling agent is experienced directly by anybody who tries to flout it (Durkheim 1938, pp. 2-3). Moreover it controls and assimilates to individual consciousness to such an extent that flouting it is for the most part unthinkable, and its status as moral constraint may even go unnoticed (Durkheim 1938, pp. 2-6; 1953, p. 55).

Yet Durkheim took great pains to point out the unnoticed dimension of social control to such an extent that society and moral control became to a large part synonymous. Thus the conventional wisdom, which asserted that collective morality was on the wane in modern society in deference to individualism and legalistic contracts (Tonnies 1963), was wrong. Modern society, far from being removed from the constraint of morality per se, was experiencing a new collective morality, something Durkheim called organic solidarity, which included such principles as moral individualism and the principles that sustain rational contracts, i.e. that which is not asserted in contracts but which causes people to abide by their terms (Durkheim 1933, pp. 200-229, 396-402; Giddens 1971 , pp. 69-72). As the division of labor advanced so also did the gradual replacement of mechanical solidarity with organic solidarity (Durkheim 1933). Individualism, then, was a morality collectively arrived at, collectively shared, and collectively enforced (Durkheim 1933, pp. 172-228).

That modern society displays the famous twin features of exteriority and constraint no less so than elementary societies is no happenstance of history. Moral constraint is indeed the essence of collective life. When individuals confront moral reality, they are confronting society; society and morality are one (Durkheim 1933, p. 228). Thus a society lacking these twin features is inconceivable, as is a legal contract without a commitment to follow it (Durkheim 1933, pp. 200-206). Yet as it happens, societies can vary with respect to the extent to which they display these twin features. Abrupt social changes, for example, can limit a society's regulating power, as can rapid evolutionary changes that outstrip the development of appropriate regulative morality (Durkheim 1951). The term
Durkheim used for this kind of condition is anomie, i.e. any reduction of regulative power of society to a state sufficient to be called pathological. Its pathological status is reflected in individual consciousness as a state of anxiety, a sense of moral groundlessness, with dire consequences that in extreme cases can lead to suicide (Durkheim 1951, pp. 241-276). Anomie's most essential referent, then, is a situation that runs roughly opposite to that of a healthy social organism. Its limit, or total anomie, would be precisely the absence of any sort of society whatsoever: a dead social organism, to push Comte's analogy a bit.

If "exteriorty" captures the sense in which society is more than the sum of its members, then "constraint" directs us to an examination of moral regultion. What, in a healthy society, is regulated? One answer is human behavior. And it is understandable why so many analysts concentrate on Durkheim's contribution to the causal factors in behavior. Durkheim himself laid heavy emphasis on it throughout his work. Moreover this dimension of Durkheim's theory, combined with supporting interpretations of Max Weber and others, has been useful in solving the Hobbesean problem of social order, a question which itself is posed in behavioral terms (Parsons 1937). The solution most prominent is voluntary socialization into a common culture, where culture consists of norms, values, roles, and so on (Parsons 1937, 1951). Under this treatment of Durkheim, society's regulative force becomes normative, or, more precisely, it becomes norms. In modern terminology, norms of society are internalized into individual consciousness where they govern behavior even as they retain their exterior status in institutionalized expressions (Berger 1963; Berger and Luckman 1967; cf. Durkheim 1953, p. 55). And, on the other side of the Durkheimian moral spectrum, anomie becomes "normlessness"' (Merton 1968).

To view norms (or normative rules) as the sine qua non of Durkheimian moral regulation is an understandable reading but not the only possible reading. Certainly no one would deny the importance of norms to moral regulation; within commonsense terms, moral regulation means following rules. Durkheim made many references to moral rules that suggest that this may have been exactly what he had in mind (Durkheim 1938, 2-3). And yet we see in the work a larger family of like terms that together denote "social facts" but which are not synonymous with norms or rules. That is, "moral rules" is a member of this class but does not exhaust it. Other terms that weave in and out of Durkheim's work include: "a collective force of a definite amount of energy" (Durkheim 1951, p. 299), "moral conscience" (Durkheim 1933, p. 42), "social currents"' (Durkheim 1938, p. 4), "a unified system of beliefs and practices", (Durkheim 1947, p. 47), "ways of thinking and 
feeling" (Durkheim 1933, p. 172), "very strong collective sentiments" (Durkheim 1938, p. 67), "a state of conscience [which] is a source of life" (Durkheim 1933, p. 96), and "the very society itself' (Durkheim 1933, p. xlviii). Of course the most famous and comprehensive term he used is collective conscience.

One reason for suspecting that something beyond rules per se is requisite for moral regulation runs parallel to Durkheim's observation that legal contracts do not enforce themselves without an underlying moral commitment to contract-following that itself is not in the contract (Durkheim 1933, pp. 200-229). At times it would appear that this simply means that such specification is not necessary because it is already known by everyone, as is the case with morality in general in mechanical solidarity (Giddens 1971, p. 75). But could this commitment be written into the contract? What then would cause anyone to abide by its terms? Could the entire supporting morality be expressed? This question amounts to asking whether an entire collective conscience, whether of a mechanical or organic sort, could be analyzed in terms of rules. A negative answer would suggest that rules are not more sufficient to moral regulation than legal contracts; one might suspect that rule-governed regulation presupposes a Durkheimian "moral something"" (cf. Collins 1981; Giddens 1971, pp. 88-89; Takla and Pope 1985). Yet we have little to go on here. Our own views on this question will come up shortly; for now suffice it to say that Durkheim studied legal codes as an index, as a "visible symbol", of moral solidarity, a phenomenon which for him was not directly measurable (Durkheim 1933, p. 64).

More important to our immediate discussion is the suggestion in Durkheim's later work that society governs not only human behavior but the human experience of objective reality as well (Collins 1985, p. 150; Parsons 1968, p. 314). That is, the categories of thought that provide for a recognizable existence in an orderly world, including notions of space and time, derive from society and arise from the manner in which society regulates human experience (Durkheim 1947, pp. $10-14,440-443)$. Indeed, mechanical solidarity indicates a circumstance in which society and reality are one: "For the Australian, things themselves, everything which is in the universe, are part of the tribe; they are constituent elements of it and, so to speak, regular members of it; just like man, they have a determined place in the general scheme of organization of the society." (Durkheim 1947, p. 141) What might be termed the ultimate reality of a society, the god in the society, that which embraces all knowable reality and sees beyond what any individual knows, is equivalent to that very society (Durkheim 1947, p. 206). The sacred energy shared by sacred objects, which among North American Indians and Melanes- ians is called mana (Durkheim 1947, p. 194), is symbolized in Australia by the totem which simultaneously symbolizes the identity of the clan group (Giddens 1971, p. 109). The unity expressed in elementary ontological systems "merely reproduces the unity" of mechanically based solidarity (Durkheim 1947, p. 145).

As the division of labor advances and as mechanical solidarity gives way to organic solidarity, this unity of world vision breaks down (cf. Berger, et al 1973, pp. 63-82). More precisely, it recedes into the background as supporting axioms for more complicated systems of thought and experience, mimicking the advancing complexity of society (Durkheim 1947, pp. 431-447; Giddens 1971 , p. 114). In short, knowledge (which is to say knowledge of the real) becomes diversified, such diversification finding its resting point on an "ultimate" unifying principle of moral rationalism, or rational individualism. ' Thus in the modern world, no less so than in earlier cultures, society remains the wellspring of the possible when it comes to experiencing the world, however, complex the world is found to be. Cosmologies, ontologies, and all of their derivitives, which is to say entire systems of thought, including those of the natural sciences, are socially derived (Durkheim 1947, pp. 13-20). Such insight dovetails nicely with what was later to be called the sociology of knowledge and Mannheim's (1936, p. 3) insistence that individuals do not think alone but participate in thinking.

This dimension of Durkheim's late work, the moral regulation of reality was not as fully developed by Durkheim as were his earlier insights (Coser 1971, p. 140). But it is apparent that when people experience objective reality, they experience in a mode identical to the empirical features of Durkheimian society: reality is experienced as external to each individual and as constraining each individual's experience of it. That is, reality displays, in experience, an organization all its own that transcends individual consciousness and which cannot be experienced in any old which way the individual chooses (Pollner 1970, 1974). The individual is obliged to experience the world in certain ways and not others, such obligations experienced as arising from the objectively arranged nature of reality as such. This independence of reality from the subjective knower appears to be essential for anyone to experience an objective reality. In Durkheim's terms, however, this independence is the independence of society from each person, and the obligation to experience

\footnotetext{
${ }^{1}$ Just as moral individualism is collectively shared and therefore not literally individualistic, so moral rationalism rests upon non-rational commitments to rationality and is not itself literally rational. See Collins 1985, pp. 129-131.
} 
reality in certain ways is nothing more nor less than socially derived moral constraint.

The consequences this shift in emphasis to Durkheim's later work has for anomie theory will be dealt with below. For now, we note that anomie, as a condition of reduced social regulation to a pathological point, as a strain toward the opposite of moral regulation whose natural limit is the absence of external society and moral constraint, is a state within whose terms the individual is unable to experience reality. Better, it is a state that has no terms. It is, strictly speaking, a non-state, a no-reality, an absence of anything to experience. And insofar as objective experience must be experience of anything, the consequence of anomie for the individual is the absence of any sort of objective experience.

\section{Anomie and Normlessness}

Most sociologists are quick to associate anomie with " normlessness". Indeed, "normlessness"' is something of an institutionalized definition of anomie which finds expression in secondary discussions of Durkheim's work, in textbooks, and on introductory sociology multiple choice exams. This equivalence has become almost a basic sociological lore, especially for those who teach the subject, a fundamental precept of a working discipline.

Yet it was not Durkheim who introduced the term "normlessness." Anomie was first used that way by Merton (1968, pp. 185-214) in his well known "Social Structure and Anomie" as a logical extension of the Parsonian solution to the problem of social order. ${ }^{2}$ Here Merton describes societal conditions in which there is a severing of cultural ends and institutionally prescribed means. Such a condition puts an individual in an untenable dilemma. No matter what the person does, he or she cannot embrace both the cherished ends and the prescribed means without guaranteed failure. The anxiety this produces, then, is a consequence of anomic circumstances in the society, i.e. circumstances that are not features of the individual but which have consequences for individual behavior.

While Merton makes only occasional references to Durkheim, and while an exact derivation from Durkheim's work has not been spelled out (see Clinard 1964), Merton does introduce "anomie", in the following manner:

\footnotetext{
2 "Anomie" has a Greek origin meaning "lawlessness." However, etymology is not the best method of grasping the meaning of a term in its disciplinary context (see Spector and Kitsuse 1977, pp. 8-12), nor does it set acceptable parameters governing how a term should be understood in the future. Moreover, "law" is equivocal.
}

As this process of attenuation continues, [whereby people prefer technically efficient over morally prescribed means], the society becomes unstable and there develops what Durkheim called 'anomie' (Merton 1968, p. 189), (or normlessness).

Seldom has such an innocent remark played such a decisive role in the historical understanding of a concept. Whether it is to be taken as a thesis, an interpretation, or simply another passing reference of no major consequence to Merton's overall theory, the anomie-normlessness connection continues to be introduced in such a casual, nonreflective manner that the equivalence as an assertion almost escapes detection. Indeed, the connection is most curious where the equivalence is alleged to be inherent in Durkheim's own writings. ${ }^{3}$ A few examples will suffice:

Such a state of affairs Durkheim calls anomie, a term that refers to a condition of relative normlessness in a whole society or in some of its component groups. (Coser 1971, pp. 132-133).

What Durkheim referred to as anomie can be otherwise termed a state of "normlessness", (Clinard 1964, p. 7 under a heading "Emile Durkheim and Normlessness"').

Even where normlessness is not identified by name, the status of anomie as the absence of norms is in the background, as in the following theory textbook's discussion of anomie:

The only answer to the question of control, Durkheim concludes, is society; that is, only social norms can set the limits, make aspirations reasonable; in short, tell people how much is enough. (Abrahamson 1981, p. 78).

We can understand why functionalists preoccupied with norms as determining factors in normal human affairs would sieze upon "normlessness" as a definition of anomie, for anomie is precisely the opposite of normal human affairs. But whatever utility "normlessness"' has for general functionalist theory, simply calling it anomie does not add to that utility except by way of providing an aura of Durkheimian respectability, a respectability that cannot be derived from Durkheim's writings. Thus the concept "normlessness" cannot rise above the limitations of its uniquely functionalist home; moreover, inextricably connecting Durkheim's powerful concept to functionalist "normlessness" unfairly saddles it with these

\footnotetext{
${ }^{3}$ Writing historically, Meštrović and Brown (f.c.) argue that Durkheim never intended anything at all like normlessness when he wrote about anomie. Their derivation of anomie as derangement and anomia as sin (see Meštović 1985) move beyond our immediate concerns; however we agree with them that functionalist derivations of anomie as normlessness are idiosyncratic and peculiar.
} 
same limitations, and to the detriment of sociological imagination. One purpose of the present paper is to transcend these limitations.

\section{Suicide and Deviance}

If the anomie-normlessness connection has passed into the official lexicon of sociology disembodied from its embeddedness in the functionalist solution to the problem of order, this equivalence has generated at least one other retrospective reading of Durkheim that can be overridden with closer inspection. This has to do with the common assertion that Durkheim's Suicide was, after all, a study of deviance, indeed the first classic study of deviance. The discussion generally runs as follows: Durkheim created anomie theory to explain one kind of deviance; Merton expanded Durkheim's theory to account for a wider variety of deviant behavior (Cohen 1968, p. 148; Coser 1971, p. 133; Nisbet 1974, p. 209; Thompson 1982, pp.120-121). This reading is understandable on two counts. First Dunkheim himself discusses suicide as an anathema to the moral community, an act that violates the sacred principles of the collective sentiment (Durkheim 1951, p. 337). Secondly, Merton's article (1968, pp. 185-214) is indeed a pioneering work in the sociology of deviance, where deviance becomes members' adaptations to the dilemma posed by the disruption between means and ends. Merton provides an analytic typology of adaptation in terms of the acceptance or rejection of means and ends which neatly embraces the categories of conventionally recognized forms of deviance, e.g. crime, drug addiction, mental illness, and so on. And he identifies the provocative dilemma with Durkheim's seminal term, anomie.

But there is another suggestion for Durkheim's interest in suicide, one which we prefer to emphasize: its uniquely private character. That is, suicide appears to be a thoroughly individualistic phenomenon (Giddens 1971, p. 82; cf. Collins 1985, pp. 122-123).

Thus it provided a perfect test for Durkheim's entire methodological approach to the study of human behavior, a critical test most likely to invite failure. In Suicide, Durkheim elaborates upon many of his central notions concerning the relationship between the individual and society, the nature of moral regulation, and anomie. As an empirical work, it was, of course, a leading coup for sociology.

To be sure, Durkheim's interest in crime and other unusual behavior is legend. Whether it is fair to call this an interest in deviance, as postParsonians conceive of it in terms of the "problem" of deviance, is an open question. But certainly his discussion of crime and individuals at odds with society has a distinctively different flavor from that of his suicide study, specifically his discussion of anomic suicide.
This difference, in fact, can be found even within Suicide in the distinction between Durkheim's treatment of egoistic and altruistic suicide on the one hand and anomic suicide on the other. Egoistic and altruistic suicide are both manifestations of social control, that is collectively enforced morality. In the first case, what is otherwise a perfectly healthy social organism (non-anomic) promotes and enforces a morality of such heavy individualism (Durkheim 1951, p. 360 - "Our very egoism is in large part a product of society") that a person is required to depend upon his or her own efforts whether up to the task or not. Troubles and failures in handling difficulty, combined with proscriptions against seeking or receiving help, may lead to suicide (Durkheim 1951, pp. 152-216). With altruistic suicide, what is otherwise a healthy social organism (non-anomic) promotes and enforces a morality of the other extreme-total emergence into the collectivity. Here the individual loses all sense of personal identity; the collectivity is all, and the individual's survival is secondary to the survival of the group, hence suicide when the occasion warrants it (Durkheim 1951, pp. 217-240). So the distinction between egoism and altruism is not that of underrregulation and overregulation, but one of the degree of social integration that is morally regulated (Giddens 1971, p. 85). Thus these two kinds of suicide are neither individualistic or private.

Suicide is not itself prescribed, and in that sense is, to use the modern expression, deviant. And it is a deviance which resonates with some of Durkheim's other analyses of disapproved behavior in relation to moral order. In Sociology and Philosophy he states, "The principle of rebellion is the same as that of conformity. It is the true nature of society that is conformed to when the traditional morality is obeyed, and yet it is also the true nature of society which is being conformed to when the same morality is flouted." (Durkheim 1953, p. 65, quoted in Nisbet 1974 , p. 210). Throughout, Durkheim maintains that morally disapproved behavior arises from the very moral constraint it rebels against and in that sense is normal. And once again, this resonates profoundly with Merton's italicized purpose of "Social Structure and Anomie": "Our primary aim is to discover how some social structures exert a definite pressure upon certain persons in the society to engage in nonconforming rather than conforming behavior." (Merton 1968, p. 186)

But anomic suicide cannot be of this general category, for anomie exists precisely to the extent that society fails to regulate. Anomic suicide does not emerge as a distorted conformity to moral order, for it is precisely moral order that is lacking. In its logical extreme, society and morality cease to exist for an individual, throwing that individual back upon his or her private resources in a manner radically different from that of the most extreme 
form of moral individualism. Anomie represents the dropping away of moral facts from the individual leaving him or her no place to stand. It is the reduction of the twin features of society, exteriority and constraint, to the point of phenomenal non-existence. Combined with Durkheim's working insights in The Elementary Forms of the Religious Life and with our arguments above, it is the withdrawal of reality itself and the possibility of objective experience. Here the individual cannot know not only what to do but also what to think (Parsons 1968). It is no wonder, then, that he or she would manifest symptoms of withdrawal, including pain and anguish. And while Durkheim's casualties were not confronted with the allegedly impossible state of "total anomie", it seems reasonable to suggest that the logical limit of anomie on the societal level is, on the individual level, precisely suicide. Suicide becomes the behavioral manifestation of the dropping away of society, i.e. the death of culture and moral regulation. This is perfectly compatible with a more general sociological supposition: as goes the society, there also goes the individual. ${ }^{4}$

One further comment before we procede. Durkheim had quite a lot to say about the necessity and inevitability of crime, this tied to the logical impossibility of universal and absolute conformity (Coser 1971, p. 142) and to the fundamental tendency of people to allow whatever the "outermost" extreme behavior happens to be count as crime (Durkheim 1938, pp. 67-70). Thus whatever specific behavior is eliminated, something would always be crime. Durkheim said crime was moreover necessary for the maintenance of moral authority, for it was only in the recognition and punishment of crime that the content of the collective conscience was recognized, reaffirmed, and celebrated (Durkheim 1933, pp. 85-103). It should be evident that this is not the kind of "deviance" indicated by anomic suicide, that is,

\footnotetext{
${ }^{4}$ Durkheim hypothesized a fourth kind of suicide, a possibility he never developed: fatalism. Logically it is suicide due to "overregulation" (as opposed to altruism) as it represents the polar opposite of anomic suicide due to underregulation (as opposed to egoism). Yet it is difficult to conceive what overregulation would consist of on this scale. What little Durkheim has to say about it (Durkheim 1951, p. 276) suggests he was thinking of tyrannical rule or despotism, i.e. social regulation oppressive to the individual and from which there is no appeal. However, this possibility flies in the face of all he says elsewhere about the nature of morality: pure force is not moral, nor is movement in that direction a cure for anomie. Regulation is characterized as moral by its status as an external force that assimilates to individual consciousness. Thus fatalism would seem to suggest too much of a good thing: moral regulation. Probably, in keeping with the organicist analogy, the term makes no more sense than over-health with respect to a biological organism.
}

suicide as the result of anomie. With anomie, the collective conscience is something on the wane, not a force being violated or conformed to by the victims of its withdrawal. In that sense, anomic behavior cannot be necessary or normal in Durkheim's sense. Crime, on the other hand, is normal and necessary so that the collective conscience will not wither and recede from public visibility. In short, and Merton notwithstanding, crime is necessary to prevent anomie. ${ }^{5}$

\section{THE SOCIAL CONSTRUCTION OF REALITY}

To summarize our argument so far: 1) The imposing and "pregivenness" of objectively organized reality corresponds to the exteriority and constraint of society. 2) Society governs reality and objective experience, not just overt social action. 3) Social constraint may involve more than just norms. 4) Anomie is the variable withdrawal (or absence) of exteriority and constraint, moral regulation, society itself, and with it reality and the possibility of objective experience. 5) A consequence of anomie for individuals is anxiety and dread, phenomenal realitylessness. 6) Anomic suicide is not a rebellion against a collective spirit but a consequence of the withdrawal of a collective spirit from the individual.

These points we have made following Durkheim. We now wish to develop these points in relation to recent findings and developments in sociological theory. Here we mean to focus upon a diversified body of material concerned with the social construction of reality and to determine its relation to anomie-no small task, as these theorists have by and large abandoned anomie to functionalism, turning their attention to the process whereby objective reality is created and sustained. We intend to show that anomie is critical to an understanding of these processes. We also intend to show that while our arguments move beyond Durkheim's sociology, they are not inconsistent with it. In the next section we shall add examples to our discussion.

\section{Exteriority and Constraint}

Social constructionism encompasses a wide range of theory, including symbolic interactionism (Blumer 1969; Hewitt 1976; Manis and Meltzer 1967; Rose 1962; Shibutani 1961), labeling theory (Becker 1963), all manner of existential and phenomeno-

\footnotetext{
5 This is an interesting side issue that could be a separate topic for the sociology of deviance. If normlessness causes deviance and deviance prevents anomie, then normlessness prevents anomie and cannot therefore be anomie. "Normlessness prevents anomie"' is an odd way of talking, but it is an oddity that derives from simultaneous respect for modern functionalism and for Durkheim, two views that may be incompatible.
} 
logical sociology (Douglas and Johnson 1977; Psathas 1973), dramaturgical sociology (Goffman 1959, 1961, 1967, 1974; Brisset and Edgley 1975), and ethnomethodology (Garfinkel 1967) plus a variety of specialized expressions of the perspective, including Berger and Luckmann's (1967) sociology of knowledge and Lyman and Scott's (1970) sociology of the absurd. A common thread in all of this work is the notion that the constraint imposed on an individual's experience of reality does not derive from an objective ordering of the external universe but rather from activities and responses of other people. This insight has occasionally been mistakenly expressed as a competing version of reality itself, a description of reality as inherently meaningless, as in Lyman and Scott's (1970, p. 1) assertion that "the world is essentially without meaning," but the overall thrust has been to transcend questions about the nature of reality and to focus upon its production in human activity within concrete social settings. This activity is found to stand in relation to reality (or knowledge of the real) as does musical composition in relation to music (or the experience of a composition as "right"). Thus to describe the final product as "out there" independent of human activity is to disembody it from its source, to reify it - such reification an essential ingredient of human activity, to be sure, but not the least bit appropriate for social scientists studying this very activity.

Durkheim articulated the congruence between reality and society; yet functionalist versions of society have rendered the heart of that insight useless by taking their macro-society for granted in precisely the same way societal members take reality for granted. Social constructionists have pursued Durkheimian insight by recognizing that society itself, i.e. functionalism's macro-entity, is no more independent of human activity as an opaque and determined phenomenon than any other kind of reality (cf. Collins 1985, p. 125). That is, society does not come ready-made, divisible into races and socioeconomic classes, nations and regions, genders and political categories, friendly and unfriendly people, and so on (Banton and Harwood 1975; Miles 1982; Garfinkel 1967, pp. 116-185; Zimmerman and Polner 1970). Indeed, no one ever "sees" this macro-entity any more than anyone ever "sees" total reality. Instead we see evidence of it in everyday life (Garfinkel 1967) and in formal documents, data, and research findings that were in turn created by people working in concrete settings (Cicourel 1964, 1968; Cicourel and Kitsuse 1963; Smith 1974). That is, people organize society just as they construct reality in general. To treat observable documents and observable activities as indices (methodologically speaking) of a non-observed entity is to disembody them from their production and to reify them, i.e. to reify social structure (Maynard and Wilson 1980).

And yet people experience the natural organization of society, they experience the reality of objective crime statistics, just as they experience the "really real" nature of any other kind of organized reality (Pollner 1970, 1974). This is not an illusion but a manifestation of empirically observable moral constraint experience imposed by people on each other in concrete settings. That is, people are not "free" to create anything they want in any way they want whenever they want; reality construction is neither individualistic nor arbitrary (Hilbert 1981, 1982). ${ }^{6}$ Rather reality construction is a social process, subject to sanctions critical to practical living.

Essential to the whole experience of objective reality is the use of the language (Sapir 1949; Whorf 1956; Vygotsky 1962). Ethnomethodologists speak of linguistic categories and partially formulated theories as cultural resources (Zimmerman and Wieder 1970; Zimmerman 1974) or conceptual idealizations (Hilbert 1981, 1982) that societal members gloss (Garfinkel 1967) in the production of particulars simultaneously glossed, the end result being a sense that the particulars elaborate upon the underlying patterns previously known to members while at the same time gaining their identities as factual matters through association with these same patterns (Wieder 1974, 1974a). Again, none of this is done at random but with an eye toward social competence. People constructing reality are as a matter of course cognizant of the accountability of their work and the role of others in determining what the product amounts to, its adequacy, its conformity with real and established facts, and so on (Garfinkel 1967). This includes strategic attention to abstract conceptions of "others" beyond the local setting whose past and potential participation is only imaginable through tacit and partial knowledge of the practical routines of social organizations (cf. Collins 1981).

This social dimension of reality extends moreover to realms which societal members hold to be wholly private or individualistic. We know from the work of Cooley (1902), Mead (1934), and Vygotsky (1978) that even the very notion of the self as that which thinks, feels, and perceives, the individual personality as the container of consciousness, is itself subject to cultural processes. That is, the individual perceives itself not by turning inward and viewing itself, as it were, directly, but by turning outward, "taking the role of the other" (Charon 1979, pp. 97-110), and viewing itself as a cultural object, an object whose nature is just as subject to social sanction and public display as is any other (Bem 1972). Thus there is no essentially

\footnotetext{
${ }^{6}$ See Coser (1975) for this common misconception of ethnomethodology and Zimmerman`s (1976) reply.
} 
private knowledge of the self. This insight has been extended to the perception of one's "internal state" as a consequence of induced physiological arousal (Schachter and Singer 1962; Becker 1953) and to the perception of pain (Kopel and Arkowitz 1974; Zborowski 1969). In a manner consistent with our remarks above, for each individual all of this experience is subject to constraint derived from the activities of other people; yet it is by virtue of such constraint that such experience is possible, that is, experience of objective internal reality.

And so the Durkheimian "social facts," no longer the reified society yet still "outside" the individual, have been shown by recent investigators to be decidedly empirical, decidedly available for scientific scrutiny (cf. Collins 1981). They are there for members too, who typically experience them as constraint imposed by an implacable reality, or in some cases by what they take to be "the society". Thus we have recovered a basic Durkheimian fundamental: the congruence of reality and society, here society becoming the social processes whereby society and reality are produced and managed. This squares nicely with Garfinkel's (1967, pp. 7-9) notion of "reflexivity," or the sense in which a description is part of the setting it describes. This also squares nicely with a Durkheimian diversification of reality in organic solidarity, such diversification rooted in a common bond-social competence, situated rationality, and a commitment to a view of comprehensive reality as organized, ultimately selfconsistent, and ultimately independent of human activity, if momentarily unknown or even unknowable in its entirety (Johnson 1981, p. 61; Pollner 1970, 1974). Thus for members, description must be performed correctly, objective experience is correct, which is to say both description and experience must correspond in some way with the actual nature of what is being described and experienced. That the phenomenon being described and experienced is simultaneously being organized and produced in the very description and experience is for members trivial (and probably false), but for social scientists it is anything but trivial.

\section{Social Constraint and Normlessness}

Ethnomethodology is perhaps best known for its criticism of theory that makes norms and rules a necessary and sufficient source of social constraint. Indeed, viewed ethnomethodologically, rules are neither necessary nor sufficient. Basically, ethnomethodological research has turned up the following on rules: 1) Rules cannot unequivocally prescribe anything (Wieder 1974, 1974a; Garfinkel 1967). 2) Rules are not a necessary requirement for either stable behavior or for reality production (Bittner 1967; Hilbert 1981). 3) Rules are required by members in practical circumstances or they are not required at all. That is, rules are required as a practical matter and not out of theoretical necessity for sociology or any other formal theory (Hilbert 1981). 4) People requiring rules never require absolute clarification; were they to do so, the clarification process would be potentially endless (Garfinkel 1967, pp. 36-44). 5) Part of rules-inuse is the determination of the rules that were followed in retrospect or the underlying meaning of a rule that was never specified (Bittner 1965; Zimmerman 1970, 1974). 6) No less a feature of rules-in-use is a caution exercised in knowing that whatever happens in the future may have to be accounted for in terms of some rule, even though exactly what that amounts to, either the rule or the future event, cannot be known in advance of its construction (Hilbert 1982; Wieder 1974, 1974a). 7) Rules are used by members not only as prescriptive guides and retrospective judgements about behavior, but also in the mere recognition of stable reality or standardized social structure as describable matters (Garfinkel 1967; Wieder 1974, 1974a; Zimmerman and Wieder 1970; Zimmerman and Pollner 1970). 8) Success in rule-use is not knowing a rule's intent or the mastery of routines it prescribes, but a victory in "impression management" (Goffman 1959), i.e. the ability to convince relevant others that none of this is being done at random, the demonstration of an awareness that not any account will do (Hilbert 1980, 1981, 1982). The tentative character of this work, together with the constraint imposed that it be done well, which is similar in many respects to a musician who however thoroughly trained in composition nevertheless has to compose something original that somehow accords with that training, commends to our attention the ethnomethodological characterization of this work as "artful practices".

Most important for our purposes is the observation that rules are not always required for stable social life, that is sometimes, perhaps even most of the time, members get by without rules (Hilbert 1981, 1982). Bittner's (1967) study of the peace keeping tactics of police on skid row brings this home most forcefully. Here the police regard their work as deliberate, stable, and organized, indeed to a degree that exceeds the carefulness of the medical and legal professions. Yet they are unable to identify rules that govern their activity, instead judging competence as an ability to improvise, not seeking "to defend the adequacy of their method against some abstract criteria of merit." (Bittner 1967, p. 712) Again, improvisation means improvising skillfully; not just any action is competentbecause police do not allow just any action to count as competent. ${ }^{7}$

\footnotetext{
${ }^{7}$ Their unwillingness to allow just any old behavior pass as competent police work is an empirical example of Durkheimian constraint, and it underscores the necessity
} 
Thus rules stand in relation to behavior and perception in much the same way as do "motives" in Mills's (1940) classic piece. Indeed "motives" may even be a special case of rule use. The point here is that when rules are not required, not called for, when behavior is non-problematic and routine, where members take their realities and routines as stable and organized at face value, then rules, like motives, play no part in the production of that routine. This is so unless there are empirical reasons to suspect otherwise. To insist on a priori grounds that there must be rules operative somewhere in the background is to organize society on one's own terms, the theorist's terms. At this point it is the theorist who requires rules in the very identification of the alleged phenomenon. Such is tantamount to abandoning the production of society as one's topic in favor of producing it, which is to say reifying it, oneself (Hilbert 1981). ${ }^{8}$

\section{Anomie and Lack of Social Accountability}

The above considerations lead us to reject "normlessness" as an acceptable reading of Durkheim's anomie. The conventional interpretation is dependent on the idea that norms are required for behavior to be organized. If we adopt this translation, though, what are we to make of the "normless" people we see everyday, for example the subjects of Bittner's (1967) study? If norms are not required at every turn, then anomie cannot be normlessness unless we are prepared to say that social order itself can be anomie - and that violates the spirit of the concept.

Instead we are redirected to Durkheimian moral regulation and our relocation of it from the reified society, a product of moral regulation, to empirically observable social constraint. We repeat that it is in these processes that individuals are regulated, now adding that such regulation is neither precise nor determinable in advance of its recognition. But

of "crime" in Durkheim's theory for sustained moral life as such, here the simple recognition that competent work is possible. For if anything is competent, then nothing ever is, i.e. the very idea of social competence is negated.

${ }^{8}$ This is not of course a general criticism of all forms of social research but only those that are specifically directed toward the theoretical problem of order. Elsewhere we have found that tacitly different solutions, including functionalism and some forms of both ethnomethodology and symbolic interactionism, share in this confusion in significant ways (Hilbert 1981). Certainly attempts within the artificial intelligence community to program computers with cultural competence suffer from these confusions (see Dreyfus 1979). But most social research, including survey research and any of the so-called "applied" social sciences, are probably not touched by this criticism when taken on their own terms. They can still remain, of course, grist for the sociologist's mill on other grounds. people regulate each other and they do it with an eye toward "reality," "truth," "society," "objectivity," "fact," (etc.) both as concepts they can mobilize in efforts to affect each other and as idealizations they have to respect in whatever their practical efforts happen to be. And again, they experience their mutually accomplished constraint as an imposition from the outside, from the very organization of reality itself.

If anomie is classically understood as the inability of society to regulate, then it will reemerge here as trouble in members' artful practices, in the production of an exterior and constraining reality. In whatever form it comes, the absence of social constraint will have the consequence of cancelling the exteriority of experienced reality for the individual. This phenomenon we identified above as reality withdrawal, and the ultimate outcome for the individual should be as classically hypothesized: anomic anxiety. ${ }^{9}$

\section{THREE EXAMPLES}

"Normal" conditions prevail when members can draw upon cultural resources to construct reality in socially accountable and sanctionable ways. While these resources cannot enforce themselves or prescribe the reality to be discovered, they exercise constraint in and through their use by relevant others. Thus their use is neither arbitrary nor literally prescribed. Anomic conditions prevail when the use of cultural resources is sanctioned arbitrarily or not at all. Arbitrary sanctioning produces a sense of irrelevance regarding what could be said or understood about the world, i.e. no account will do, anything is incorrect. No sanctioning whatsoever produces essentially the same thing - any account will do, anything is correct. In either circumstance, what is lacking is

\footnotetext{
${ }^{9}$ One could argue that our recommendation reifies anomie just as functionalists reify social structure (Maynard and Wilson 1980). Such an argument misconstrues the social constructionist analysis of functionalism as a methodological critique. It is not a methodological critique insofar as constructionists, particularly ethnomethodologists, draw their distinction not in their method but in their topic. They share many research methods with functionalists but they use them to study other things, namely the origins of social structure in concrete human life. A reification of social structure obscures this phenomenon from the analyst's view. But the reification of something, whatever one's topic is, is surely an essential ingredient of social life, no less so for sociology and no less so for ethnomethodology. So one could say we are reifying anomie here only in the sense that social constructionists reify the existence of language, cultural resources, social processes, and the rest. But if that's a criticism, it's a criticism that is without remedy, it's a criticism that could be leveled against any science, and it's a criticism we wouldn't want to make.
} 
social accountability. We therefore understand anomie as "absence of social accountability," circumstances in which all possibility of objectively experiencing reality correctly is withdrawn.

In this section we examine three examples of our approach to anomie. Two of these were attempts on the parts of social researchers to deliberately sabotage members' accounting practices; of these two, the first failed in ways that are nevertheless instructive, and the second was highly successful, though of limited duration. The third is a naturally occuring phenomenon related to the experiences of chronic pain sufferers and is not at all of limited duration.

\section{Approaching Anomie: "Nonsense" as Meaningful}

In the mid-1970's we attempted to disrupt members' reality construction methods by assigning about one hundred students a reality-problem for which no solution could be entertained (Hilbert 1977). Yet because this was presented as an optional class assignment with potential credit toward a final semester's grade, social constraint would theoretically be experienced such that students would to some degree require a correct solution. The task was designed in such a way as to be readily distinguishable from "difficult" tasks for which solutions could be written off as "unknown" or about which students could withhold judgement pending further investigation. The task was to be beyond the horizons of solvability, yet presented as though a solution were imminent. Thus we might expect some of the "anomic terror" (Berger and Luckmann 1967, pp. 102-103) that accompanies the awareness that one's efforts to find reality are useless and that any attempt is just as good as any other.

The task presented was that of determining an actual course of events in light of five eye witness accounts. Instructions directed students to sit as jurors upon the five versions in an effort to discover "what really happened". These five "versions" were arbitrarily selected stories solicited independently from five people who had been asked simply to write a two to three page description of an event, any event, real or fictitious. Thus the stories were unrelated to each other, not historically derived from a core event as implied by the instructions to students. The stories included: a) a description of a sensitivity training session, b) an account of the loss and recovery of some important papers, c) a story about a water-skiing accident, d) a report concerning the establishment of a new biology laboratory, and e) a story about someone falling into a ravine and becoming paralyzed. It was expected that the unrelatedness of the stories, together with the instructions that they be seen as related, as variously biased perspectives on one event, would constitute a task that students would inevitably find unfulfillable. Student responses took the form of short essays (Hilbert 1977, p. 27).

While students were unable to identify a core event or hypothesize the possibility of ever doing so, their attempts failed to produce global confusion. Indeed, students were able to use the very existence of this assignment as documentably "nonsense" to document a reasonable, coherent, and recognizable reality, a reality in which "nonsense" assignments of this sort could be expected and expected to cause precisely the kinds of confusion students were experiencing. Students used "nonsense" categories as conceptual resources for organizing, identifying, and explaining the task itself, and they did so in ways identical to the ways in which members document any other kind of reality. They used and glossed general and equivocal criteria for "nonsense" together with idiosyncratic features of the assignment (e.g. "A bay cannot be related to a drainage sewer or a laboratory to a ravine."') to produce a case for the assignment as nonsense in reality rather than simply an assignment capriciously called nonsense as an excuse for giving up on it. And they maintained a sense of discoverable order by allowing for an "ultimate explanation" for the nonsense assignment, by displaying interest in finding out what the purpose was, by speculating on the instructor's intent, and so on the question "why nonsense here and now" was itself sustained as a sensible and potentially answerable question, one whose answer would eventually fit in with everything students already knew about the world (Hilbert 1977, pp. 27-29). Moreover, students' idealized sense of "nonsense" and "meaninglessness", i.e. their understanding of what "nonsense" means as opposed to their understanding of why an example of it would come up, enabled them to abandon the task as an entity worthy of their considered attention. That is, their reasoned arguments that nothing really happened (as opposed to "something we do not know about happened," or "something impossible happened," or even "that contradictory event couldn't have happened") allowed them to ignore the task completely and to ignore it in ways that are socially accountable, ways that "fit in" with members' reasoned ways of living in a familiar world (Hilbert 1977, pp. 29-30).

Thus members have at their disposal a family of cultural categories useful for saving the documentably objective character of reality whenever it is abruptly challenged, to assimilate nonaccountability to accountability. There is meaning, then, in "meaninglessness." This undercuts in no small way an understanding of anomie as simple meaninglessness (Parsons 1968, p. 196). Meaninglessness is an experienced piece of comprehensive reality, and its status as objective is subject to 
social accountability and constraint no less than any other alleged phenomenon. ${ }^{10}$

The import of this experiment to our present concerns is that it suggests the difficulty encountered in promoting anomic social circumstance. People are after all members by virtue of their mutual association in culture, and their commitments in these areas are difficult to thwart. When the challenge comes, members scramble to restore order, even where the presumed order is constructed as "without sense." Reality dies hard.

\section{Stealing Social Accountability: Contrived Anomie}

If people can gloss difficulties in reality construction with "nonsense" categories in ways that are socially accountable, their success would depend to some degree on the extent to which they are able to ignore the objects of their frustration. Had students in the previous study been jurors in a courtroom or had their very lives depended upon success in completing the assignment, perhaps their efforts at "nonsense" construction would themselves have met with failure, inviting the kind of anxiety we have been discussing. That is, the mandate to take an insoluble reality-problem seriously should reduce the abilities of members to account for their own confusion.

Many of Garfinkel's "breaching" experiments can be thought of as simulated anomie into which subjects were placed, and many of these experiments produced anomic anxiety. But most of these conditions were either of short duration, instantly repairable, or under subjects' control. An illuminating exception to this is an experiment Garfinkel (1967, pp. 58-65) conducted in which he concertedly prevented subjects from turning the situation "into a play, a joke, an experiment, a deception, and the like" (Garfinkel 1967, p. 58) or in our terms from documenting the situation in such a way that would allow subjects to justifiably ignore it. Moreover, by actively and ongoingly sabotaging subjects' sense-making procedures, Garfinkel effectively withdrew reality from subjects in ways that would not allow them immediate recovery. And he produced the expected results: profound and marked anxiety.

The situation into which these twenty-eight premedical students were individually placed was "serious." The experimenter identified himself as "a representative of an Eastern medical school who was attempting to learn why the medical school intake interview was such a stressful situation.' (Garfinkel 1967, p. 58) For a full hour

\footnotetext{
${ }^{10}$ One might argue that nonsense stands in relation to sense as crime does in relation to normal behavior, in Durkheim's sense, or incompetence to competence in Bittner's (1967) study. Both are grounded in culture and in normalizing activity. If anomie is meaninglessness, it's a type more radical than cultural meaninglessness.
}

the student talked with the "representative" about intake interviews and what kinds of events they are. Credibility having been established, the student was then asked if he or she would like to hear "a recording of an actual interview", (Garfinkel 1967, p. 58), whereupon the student was treated to a recording of a fake interview in which the "applicant" performed in a manner that ran roughly opposite to what one would expect from a successful and reasonably competent applicant. The student was then asked to assess the applicant. The "representative" responded to this assessment drawing upon "facts" from the applicant's official record, including performance information (biographical information, family background, academic achievements, charities) and characteriological information supplied by "Dr. Gardner, the medical school interviewer," " "psychiatrically trained members of the admissions committee who had heard only the recorded interview," and "other students" who had heard the interview also (Garfinkel 1967, p. 59). All of this information was contrived and created in the course of the experiment to document a successful and highly articulate applicant based on facts alleged to be in the applicant's record all along. The details were created in such a way as to directly contradict the student's every point regarding the applicant, moreover to contradict his or her every attempt to resolve this very contradiction. The essential contradiction extended to what "other students"' (other premedical students supposedly just like the subjects) had thought of the applicant, and this information was credibly presented. Following this exchange, the student was invited to hear the recording again and to reassess the applicant.

Garfinkel was in effect stealing social accountability in the very process of its accomplishment, withdrawing reality from subjects even as they were creating it. What students who were taken in did not know was that here was a situation in which "no account would do," i.e. nothing counted as correct reality perception. Their inability to arrive at this conclusion was no doubt tied to the "seriousness" of the situation, which is to say the seriousness of intake interviews in the lives of premedical students and specifically the potential hazards of social incompetence in an encounter with a medical school representative. This is to say that the stakes were much higher for these subjects than they were for the students in the last section. Premedical students needed to "know" about intake interviews, and they needed to "know" the situation they were in. Yet Garfinkel's experimental tactics withdrew the possibility of such knowledge and with it objective experience of a relevant reality. Subjects' inabilities to reject the situation as serious, to "leave the field" in Garfinkel's (1967, p. 58) terms, did not allow them to gloss the experience with "nonsense", 
categories. For students taken in, the situation was neither meaningful nor, strictly speaking, meaningless, as even that alternative-and final-normalizing strategy was beyond their immediate horizons.

Subjects varied with respect to how far they were taken in, and three were not taken in at all (Garfinkel 1967, pp. 63-67). Of those who were, dramatic anxiety was evident as they approached the point where resolution seemed hopeless or otherwise not forthcoming. Transcripts reveal students profoundly disturbed, in the throes of questioning their own abilities to judge people and situations, sometimes raising comprehensive questions about themselves as persons (Garfinkel 1967, pp. 60-63). Of the seven most profoundly perplexed, Garfinkel (1967, p. 63) says, "Their suffering was dramatic and unrelieved." Two of the three who had acted on the conviction that the interview was a hoax and who thereupon showed "no disturbance" during the course of the experiment displayed "acute suffering" when the interview appeared to be over with no confirmation of their suspicions forthcoming (Garfinkel 1967, p. 63).

This kind of suffering we term anomic, in that its nature and origins cannot be derived from individual psychology. Its cause is located outside of individual consciousness, here in the essential lack of social accountability that subjects could not be aware of but nevertheless could not help but "experience." We put quotes around "experience" to emphasize that the object of subjects' experience was not strictly or recognizably known to them; indeed its status as an "entity" in subjects' lives lay beyond their consciousness. In that sense their suffering warrants the label "content-free-or reality-free experience" in that there was nothing for them to experience. Their disorientation was unaccountable in that all attempts to account for it were similarly disorienting; their suffering was not derived from social conditions but rather from the withdrawal of any recognizable social conditions whatsoever. Subjects were, in ways more radical than would be promoted by the most extreme individualism, alone. And in terms of reality, they were, in ways more radical than would be promoted by the most extreme nihilism, nowhere.

Upon learning of the deception, subjects expressed relief, "ten of them with explosive expressions"' (Garfinkel 1967, p. 64). Unanimously they declared their abilities to return to their former views, although it is indicative of Garfinkel's success that seven subjects needed to be convinced that the news of deception had not itself been manufactured to relieve them of their damaged self images (Garfinkel 1967, p. 64). One would expect this return to familiar social settings, here the world of social psychological experimentation, to precipitate a return to reality and an end of anomic suffering. And herein lies a distinction between Garfinkel's subjects and those we discuss in the following section: the temporary status of their trouble.

\section{People in Chronic Pain: Natural Anomie}

In a recent study (Hilbert 1984) we interviewed twenty-two chronic pain patients and conducted ethnographic observations at two pain control clinics in the midwestern United States. Our objective was to identify dimensions of pain that were distinctively social; however as we moved into the study, more intriguing phenomena emerged, something we identified as acultural dimensions of pain. That is, chronic pain sufferers were found to be experiencing troubles that transcend the problem of physical pain or related pain psychology. These newly identified troubles are identical in essential respects to the troubles of Garfinkel's (1967) premedical students of the last section. They revolve around the problem of meaning in ways that defy the use of "nonsense" categories to escape the trouble. But unlike Garfinkel's subjects, pain patients cannot experience relief when the announcement comes that the experiment is over.

The trouble for chronic pain sufferers is this: pain is an ongoing, incorrigible "fact" for sufferers, yet it is beyond their abilities to experience as a fact in the social sense, that is as an item of knowledge (Berger and Luckmann 1967). Sufferers cannot know their pain, know what it is, know its nature, experience its identify as an objective entity, as a reality, even as they require and search for these very kinds of certainties. Their inabilities to describe and experience do not lie either in their skills and talents as persons or in the nature of pain but rather in the culture around them which provides neither the resources nor the social constraint for conceivably accomplishing the task; in that sense, culture is for these sufferers' practical concerns anomic. While most sufferers confront these troubles from time to time, the problem is most severe among pain sufferrers without benefit of each other's counsel in the creation of what Kotarbaa (1983, p. 74) calls "chronic pain subcultures."

The trouble initially begins as the sufferer gradually realizes that pain is not conforming to normal pain routine, that it is not going away (Hilbert 1984, pp. 366-368; Kotarba 1983, pp. 64-71). This has far deeper implications than one might suspect from mere reflection, for the very experience of pain as pain, as a cultural object, includes the background expectancy of its inevitable termination, even where experts may have to be consulted in severe or stubborn cases. Indeed, familiarity with pain as a normal experience is often sufficient for initially dismissing pain as any kind of serious matter at all. As familiarity fades, so also does the sense that pain is pain, i.e. 
“normal pain" (Hilbert 1984, pp. 366-370). It must be, for sufferers, something else.

A most prominent method sufferers employ to normalize ongoing pain is to attribute its ongoingness to a medical or otherwise somatic cause, something presumably present but as yet unknown. To find the cause, sufferers consult experts, most often physicians and medical specialists. Initially the search is motivated by the expectation of treatment and cure, but as the hospital visitations and diagnostic investigations turn up repeatedly negative results, the search takes a turn toward an attempt to validate the sufferer's bodily experience as a correct perception of a true state of affairs. In other words, there comes a time when a positive diagnosis could restore order to a sufferer's world, locate a sufferer's condition in medical indices and libraries, and verify a sufferer's sanity (Hilbert 1984 , pp. 368-370). Better, the search for medical clues becomes a quest for something to experience.

Thus expert consultation may exacerbate sufferers' frustrated attempts to find meaning. Many sufferers spend large portions of their lives in hospitals and clinics, changing doctors, undergoing tests, retests, and extensive diagnostic investigations which turn up nothing. Such results are official challenges from the objective social world to sufferers' subjective states: they document a state of affairs which runs roughly opposite to however sufferers might otherwise understand their physiological circumstance.

For the lucky ones who do eventually turn up a positive diagnosis, the relief is dramatic and may have nothing to do with whether or not the identified condition can be treated. One patient indicated in emphatic tones that she had been so "delighted" by the news that the problem had at last been found that she had not heard what the diagnosis was. She said that her joys would have been undiminished even if the problem had been cancer, since the diagnosis itself was proof that "there was nothing wrong with her head" (Hilbert 1984 , p. 368). This parallels the relief of Garfinkel's subjects when, following the news of deception, they were free to return to normal.

Chronic pain therefore creates problems analytically separable from mere physical pain. These problems cannot be understood by examining either the physiology or the psychology of pain, because they are not located there. They are located in the procedures people employ to construct reality and thereby objective experience, and in the cultural resources people summon to do so. Cultural resources normally employed to organize and understand pain can only be by their very sense used to construct realities which either contradict sufferers' long term practical objectives or document sufferers as objectively incapable of correctly experiencing their own bodies. For sufferers, then, such culture is useless.

From this predicament, some sufferers turn inward. They in essence abandon social methods of understanding their condition, relying instead on notions of pain as a private reality which only the person in pain can ever know, a view promoted culturally and in professional literature (Fagerhaugh and Strauss 1977, p. 24; Kotarba 1977, p. 261; Pace 1976, p. 1; Sternbach 1968, p. 1). The general understanding is that no one can feel, understand, or experience the objective character of someone's pain except the person in pain. Each person presumably has private access to the objective organization of his or her own private pain: its intensity, its character, its fluctuations, any and all patterned dimensions to pain. Under this model, pain ceases to be an object of shared understanding, i.e. a cultural object. Instead it is private. Supposedly, sufferers turning inward could study their pain and gather information about it. That way they could obtain knowledge of it, understand it, describe it if only for themselves, and thereby find meaning.

Yet these efforts fail (Hilbert 1984, pp. 373-376). Sufferers describe their failures as searching for patterns that dissipate in the finding, as intuiting patterns with unlimited variables and exceptions, as hypothesizing patterns they cannot check up on, and so on. Sometimes sufferers give up in the attempt with the conclusion that pain is too random or complex for description. A sociological understanding of this failure finds randomness not in pain but in sufferers' descriptive work. Attempts to describe an objectively arranged internal reality provide no criteria for correct or incorrect description. In short, any account will do or will not do according to whatever sufferers feel like saying, or, more precisely, whatever sufferers say. " Correct description, and with it objective knowledge, is impossible precisely because nothing (or anything) counts as correct description. There is no constraint (cf. Becker 1953; Schachter and Singer 1962; Kopel and Arkowitz 1974; Zborowski 1969).

Thus we argue (Hilbert 1984) that sufferers' private pain vocabulary is anomic. It expresses pain but is no more descriptive of it, no more true or false, than "ouch" (cf. Goffman 1981, pp. 105-106). Sufferers requiring anomic vocabulary to do the work of description will find the task impossible in ways that are essential. Indeed, even the sufferer's professed knowledge that he or she is in pain is more like a symptom of pain than a description of internal affairs. This does not mean that such professed knowledge is false; it is just that it could not be true or false. It is without

"This would be the "transcendental ego" that Coser (1975, p. 698) mistakenly identifies as an ethnomethodological view of subjectivity. This example also highlights the inadequacies of crude labelling theory discussed by Pollner (1974a). 
criterion for its own verification. Sufferers searching for verification, for reality, will only turn up endless paradoxes (cf. Sauerbruch and Wenke 1963, p. 73).

In sum, pain sufferers have troubles that transcend pain. These troubles are acultural in that they do not derive from culture or social activity but instead are manifestations of culture withheld, from social non-participation, from radically receding membership. Sufferers have puzzles to solve but are falling away from culture in whose terms it is possible to solve anything. Even "meaninglessness" does not capture the object of their experiences, for they are, strictly speaking, not experiencing anything. There is nothing, no objective phenomenon, for them to experience. They are losing reality.

These anomic troubles find some corroboration in the widely known high correlation between chronic pain and clinically diagnosed personality disorders, particularly depression (Brena 1978, p. 8; Pace 1976, p. 13; Merskey and Spear 1967; Shealy 1976; Sternback 1974; Unikel and Chapman 1978). The common sense view that such psychological stress is caused by sustained physical discomfort alone is held in general low regard by pain researchers and clinicians who hold that at a physical level most chronic pain is not very severe (Hilbert 1984, p. 369; Kotarba 1983a, p. 685; Shealy 1976). An alternative and more common view is that these personality syndromes cause the pain or otherwise cause patients to exaggerate pain; thus proper treatment would consist of one or another form of psychotherapy (Biggers 1978; Brena 1978; Pace 1976; Sternbach 1968, p. 117; Szasz 1968; Unikel and Chapman 1978). While the continued controversy over the direction of causality may generate epidemiological research (see Kotarba 1983a, pp. 687-688), our formulation provides a clear sociological theory that would predict symptoms of anxiety and depression as a complication of chronic pain no matter how benign a clinician thinks the pain is, so long as the sufferer perceives pain as sufficient for raising questions as to its cause or identity. ${ }^{12}$

\footnotetext{
${ }^{12}$ Notice that if pain description is anomic, there is no way for clinicians to determine an "actual degree" of intensity and no way for them to decide if patients' claims are exaggerated (cf. Schachter and Singer 1962). But we should still emphasize that we are not arguing conclusively for our sociogenic interpretation of survey results; our main claims to discovery are ethnographic. Epidemiologists are well aware of problems related to the direction of causality between chronic pain and clinical depression. The issue has not so far been settled in the methodological arena due to the practical impossibility of targeting a population of potential pain sufferers in advance of the pain. That is, studies to date are largely retrospective, depression being clinically diagnosed well after the onset of pain. Thus no one has ever tried to predict who will and who will not succumb to chronic
}

Moreover, Kotarba (1983a, pp. 685-687) found that thoughts of suicide are a recurring theme in the minds of chronic pain sufferers, and he ties this theme to sufferers' loss of cognitive control. Suicide is entertained as a viable alternative to chronic pain related troubles, and while actual attempts seem to be rare (Kotarba 1983a, p. 686), Kotarba found that its recurrence is sometimes mitigated by sufferers resorting to alternative cognitive systems regarding pain, i.e. meaning systems that, in our terms, allow an abandonment of the search for an objective understanding of one's condition in favor of a new understanding that accounts for the very existence of the unsolvable puzzle. Thus do religious, mystical, and other metaphysical understandings of suffering relieve sufferers' anomic dread. Our own study (Hilbert 1984, p. 369) reveals that even the label "chronic pain" as a medical condition in its own right-as documented by the proliferation of chronic pain clinics - is often sufficient to reduce sufferers' anxiety in these areas. As one patient described his relief after a two year diagnostic search: “. . . I didn't know about chronic pain, I knew I had pain period . . . Now I know there's a definite pain there.' 13

\section{DISCUSSION AND CONCLUDING REMARKS}

The power of Durkheim's anomie theory has been obscured by the weaknesses of its interpreters. Normlessness, suicide as deviance, and anomie as a cause of deviance are all consequences of retrospective readings of Durkheim which a) focus upon human behavior neglecting the cognitive, experiential dimension of Durkheim's work, b) settle on "norms" as the overarching explantory variable in Durkheim's formulation despite his discussion of the inadequacy of rules and laws in governing behavior and his suggestion that such

pain. Theoretically, however, pain researchers tend to come down on the psychogenic side precisely because a) psychology provides a model, and b) there is no competing model other than a commonsense view that pain could make one depressed. So without settling anything, we are providing a competing model based on our ethnographic identification of non-physiological and non-psychological suffering attendent to pain, and based upon anomie theory, which would predict exactly the correlations that epidemiologists discover. Thus we are resurrecting the question, providing warrant to an unpopular hypothesis, without answering it.

${ }_{13}$ One major aspect of psychotherapeutic success is not the reduction of physical pain per se but the reduction of clinical depression, this tied to teaching sufferers to live with pain, not to let it interfere with their lives. This is consistent with our view that such treatments could consist of teaching sufferers new ways of thinking about pain, new concepts for organizing it, thereby reducing the anomic reality-problem which is the source of our newly identified suffering (Hilbert 1984, p. 369). 
laws are but an index to moral regulation, and c) overlook the formal distinction between Durkheim's treatment of anomic suicide, on the one hand, and egoistic and altruistic suicide and "crime" on the other. These readings, taken together, constitute a functionalist coup according to which Durkheim himself becomes a founding father of modern functionalism and all further considerations of Durkheimian sociology are subject to the limitations of that modern orthodoxy. Thus do sociologists straining against this orthodoxy often find "anomie" a dubious concept to begin with, and thus do they surrender the concept, along with the heart of Durkheim's sociology, to the functionalist domain of expertise. ${ }^{14}$

We are suggesting an alternative. We are suggesting that a lifting of the functionalist veil reveals a very different Durkheim indeed. That is, unencumbered by textbook definitions of the essential Durkheim and his official place in the history of sociology, we see a Durkheim with a passionate interest in human cognition, the origins of both metaphysical and mundane reality in social life, and the unpleasant consequences of nonparticipation for individual experience. Moreover, Durkheim was a thoroughgoing empiricist. Thus our reconsideration of Durkheim's sociology articulates with corroborative discovery within the reality construction tradition, particularly ethnomethodology.

Against this Durkheimian backdrop, modern research designates a distinctive form of individualistic suffering that derives from the withdrawal of reality and the possibility of objective experience. Returning to Durkheim, it seems fair to suggest that his suicide victims, or the people of whom these victims were statistical representatives, tended toward this very suffering. That is, the cultural consequences of sudden and massive social change (Durkheim 1933, pp. 353-373), of sudden new affiliations and life worlds that accompany new found wealth or poverty (Durkheim 1951), would precipitate this sense of moral groundlessness and lack of social accountability. Thus we can understand Durkheim's casualties in a manner distinctively sociological, without the reversion to psychological models of aspiration,

${ }^{14}$ Randall Collins (1985, pp. 119-179) argues that modern functionalism is but one "wing" of Durkheimian scholarship, and that the other, more micro-oriented tradition, can be traced from Durkheim through social anthropology to micro-sociologists such as Goffman. This may be true, but judging from secondary textual analysis of Durkheim's theory as a topic in its own right, including textbooks which teach Durkheimian insight to our students, functionalists appear to have the upper hand in matters theoretical. Micro-analysts may be inspired by the spirit and temper of Durkheim's seminal scholarship, but they have not made their Durkeimian groundings a major focal point. To redress that imbalance is one purpose of the present paper. suggested in Durkheim's own work, that mark other recent reformulations of Durkheim's anomie theory (Ginsberg 1980).

In summation, our formulation of anomie is consistent both with Durkheim's sociology and with contemporary social construction theory in the following ways: 1) It designates the withdrawal of exteriority and constraint and their equivalence, objective reality. 2) It locates the moral regulation of reality in empirical human activity as opposed to theoretically required abstract forces. 3) It indicates circumstances in which that very human activity is unavailable. 4) It predicts anxiety and moral groundlessness (anomia) as a consequence of that unavailability. 5) It finds what it predicts, both experimentally and in the field. 6) It views anomic behavior (either entertained or manifested, e.g. suicide) not as distorted conformity, not as deviance, but as a consequence of the withdrawal of anything to conform to.

The advantages of connecting a major classical sociological theorist with an innovative contemporary empirical tradition should be apparent. They become even more apparent when we consider the paradoxes, confusions, and methodological problems that arise within the functionalist orthodoxy. We would anticipate this confusion, as functionalists explain human behavior by use of a normative order that theoretically cannot and empirically does not exist (Hilbert 1981). Thus to assert that anomie is an absence of that reified entity, which is to say an absence of something which was never empirically present to begin with, is bound to generate a wide range of methodological difficulties when it comes to its empirical recognition and measurement. And while functionalists do not cast their problems in this light, they do face the inevitable issues, within their own terms and without resolution.

For example, functionalists correctly recognize that a cornerstone of Durkheim's theory is the status of anomie "outside", individuals, in the social environment around them. Thus Merton sees anomie as a transpersonal pathological split between means and ends which has consequences for individual experience but it not equivalent to it. The question that arises within a Mertonian tradition is how to identify the phenomenon in the empirical world, how to measure it. A common answer has been aggregate data collected on individuals, the most prominent of which is the Srole scale (1956). A recognized shortcoming of this technique is that it actually measures collective anomia, the consequence of anomie, not anomie itself or anything else "outside" individuals. To treat collective anomia as an index of anomie begs the question as to what extent, and in what ways, a transpersonal phenomenon caused the observed results among individuals (see Seeman 1982, p. 84; Schacht 1982, pp. 73-80). In short, this 
technique does not supply evidence of anomie as an empirical phenomenon.

Furthermore, techniques like the Srole scale implicitly characterize the transpersonal split as an objective phenomenon which, though not scientifically observable, can be indirectly confronted, witnessed, and reported on by societal members. Thus individuals are not merely indices but also informants (Johnson 1960). The conclusion follows that there is confidence in numbers, as anomie as an objective condition supposedly could not exist for an individual alone but would have to be present for anyone. Nevertheless this approach indexes anomie precisely as members' perceptions of it; that, in turn, leads to questions regarding the reliability and accuracy of subjects' reports and the problem of "false consciousness" (Seeman 1981, pp. 126-127). These problems are without solution, and once again anomie escapes the empirical net of sociological discovery.

In our view, attempts to measure anomie as aggregate anomia compound the functionalist reification of norms with a reification of normlessness. That is, normlessness is presumed to be a real entity whose status transcends not only individual members but sociological research methods, i.e. methods of empirical investigation. And even though perception and subjective experience are used to index this entity, this only compounds the problem still further by treating members' beliefs in a nonempirical entity as evidence of that entity. To make matters even worse, that entity is not anomie. To say it is makes anomie whatever members identify as the source of their trouble; "anomie"' becomes the sociologist's term for members' phenomena: social disarray, confusion, lack of solidarity, and powerlessness. Thus we have at least a double problem: a) reifying members' perception of their troubles to the status of scientific phenomenon, and b) calling the product of members' theorizing anomie-even though anomie is supposed to be precisely that which inhibits stable perception and constitutive work. Under this vision, societal members have jurisdiction over the concept "anomie", they own it, they decide what it is, they use it to stablize experience. Under this vision, anomie is not trouble for members but a concept for organizing and explaining trouble; even members' "nonsense" attributions, discussed above, would serve as an index for anomie. ${ }^{15}$

\footnotetext{
${ }^{15}$ Another set of comments argues with attempts to measure structural anomie as indexed by dissensus and low levels of agreement among members of a collectivity (Jessor, et al. 1968). This approach, the critics say, may tend to underestimate the functional benefits of cultural heterogeneity (Seeman 1982, p. 126); moreover they presuppose a unified system of goal and values which may not exist in the best of times (Schacht 1982, p. 72; Clinard 1964, pp. 55-56). Our approach both bypasses
}

These paradoxes and conceptual difficulties have reduced the power of anomie theory and fostered the impression, especially among nonfunctionalists, that "anomie" is a concept whose utility is in doubt. Our formulation of anomie as the withdrawal of social process and reality recovers the power of Durkheim's anomie theory for modern research and it does so without falsifying the empirical social world. First, we do not reify anomie to an objective status available to all people the same way. We find anomie in the relations between the individual and the collectivity (Seeman 1982, p. 127), specifically a characteristic lack of relation. What is missing with anomie is something that would be empirically observable, not just theoretically required, if it were not missing. And its absence, insofar as the withdrawal of social control can be witnessed, is also empirical. Thus lack of accountability in Garfinkel's premedical student experiment can be theoretically understood, described, and witnessed-and produced-independently of the anxiety it produced in students. Likewise the same phenomenon can be found in the lives of chronic pain sufferers independently of the personality inventories that document depression.

Secondly, anomie need not be experienced by a large number of people for its occurrence to be diagnosed by the analyst. Indeed, under our formulation, anomie, as a circumstance "outside" the individual, may even be present for one individual. Garfinkel's experiment was not anomic for the experimenter, and the concepts, categories, and cultural resources fruitlessly employed by chronic pain sufferers were not necessarily anomic for the people around them. Likewise, an entire society, anomic for the stranger undergoing cultural shock, may be anything but anomic for natives.

Thus our formulation returns anomie to sociology as a theoretical matter and as an empirical phenomenon. Members may not experience it or know about it, even as it is present for them, just as they need not "know about" their participation in reality construction or be familiar with

and answers these doubts. First, Durkheim clearly indicates a diversification of reality and experience in an emerging organic solidarity, so in that respect the critics are correct. On the other hand, the unifying Durkheimian moral individualism, without which modern society could not exist, finds expression in reality construction as a commitment to circumstantial rationality, to situational social competence, and to a view of comprehensive reality as objectively organized and ultimately selfconsistent (Johnson 1981; Pollner 1970, 1974). It is not generally these underlying commitments that are addressed in measurements of dissensus. Moreover anomie need not be indexed by "disagreement" over these commitments but only by the withdrawal of social interaction within whose terms it is possible to live these commitments, to document their status. 
ethnomethodology at the other end of the continuum. Indeed part of our formulation is to treat anomie as the withdrawal of anything to experience. Anomia, then, is not a subjective impression of anomie that could be true or false but rather is a result of anomie, an empirical circumstance diagnosed by the sociological analyst.

\section{REFERENCES}

Abrahamson, Mark. 1981. Sociological Theory: An Introduction to Concepts, Issues, and Research. Englewood Cliffs, New Jersey: Prentice-Hall.

Banton, Michael and Jonathan Harwood. 1975. The Race Concept. New York: Praeger.

Becker, Howard S. 1953. "Becoming a Marijuana User." The American Journal of Sociology 59:235-242. 1963. Outsiders: Studies in the Sociology of Deviance. New York: The Free Press.

Bem, Daryl J. 1972. "Self-Perception Theory" in Advances in Experimental Social Psychology. Vol. 6, edited by L. Berkowitz, New York: Academic Press.

Berger, Peter. 1963. Invitation to Sociology: A Humanistic Perspective. Garden City, New York: Anchor.

Berger, Peter, Brigitte Berger and Hansfried Kellner. 1973. The Homeless Mind. New York: Random House.

Berger, Peter and Thomas Luckmann. 1967. The Social Construction of Reality: A Treatise in the Sociology of Knowledge. Garden City, New York: Anchor.

Biggers, W.H. 1978. "Emotions and Pain."' Pp. 74-81 in Chronic Pain: America's Hidden Epidemic, edited by Steven F. Brena. New York: Atheneum.

Bittner, Egon. 1965. "The Concept of Organization." Social Research 32:239-255.

1967. "The Police on Skid Row: A Study in Peace Keeping." American Sociological Review 32:699-715.

Blumer, Herbert. 1969. Symbolic Interactionism: Perspecive and Method. Englewood Cliffs, New Jersey: PrenticeHall.

Brena, Steven F., ed. 1978. Chronic Pain: America's Hidden Epidemic. New York: Atheneum.

Brissett, Dennis and Charles Edgley, eds. 1975. Life as Theater: A Dramaturgical Sourcebook. Chicago: Aldine.

Charon, Joel M. 1979. Symbolic Interactionism: An Introduction, An Interpretation, An Integration. Englewood Cliffs, New Jersey: Prentice-Hall.

Cicourel, Aaron V. 1964. Method and Measurement in Sociology. New York: The Free Press.

1968. The Social Organization of Juvenile Justice. New York: John Wiley \& Sons.

Cicourel, Aaron and John I. Kitsuse. 1963. The Educational Decision Makers. Indianapolis: Bobbs Merrill.

Clinard, Marshall B., ed. 1964. Anomie and Deviant Behavior. Glencoe, Illinois: The Free Press.

Cohen, Albert, 1968. "Deviant Behavior." International Encyclopedia of the Social Sciences. New York: Macmillan.

Collins, Randall. 1981. "On the Microfoundations of Macrosociology." American Journal of Sociology 86:984-1014. 1985. Three Sociological Traditions. New York: Oxford University Press.
Cooley, Charles Horton. 1902. Human Nature and the Social Order. New York: Scribner.

Coser, Lewis. 1971. Masters of Sociological Thought. New York: The Free Press.

1975. "Presidential Address: Two Methods in Search of a Substance." American Sociological Review 40:691-699.

Douglas, Jack D. and John M. Johnson, eds. 1977. Existential Sociology. New York: Cambridge University Press.

Dreyfus, Hubert L. 1979. What Computers Can't Do: The Limits of Artificial Intelligence. New York: Harper Colophon.

Durkheim, Emile. 1933. The Division of Labor in Society. Glencoe, Illinois: The Free Press.

1938. The Rules of Sociological Method. New

York: The Free Press.

1947. The Elementary Forms of the Religious

Life. Glencoe, Illinois: The Free Press.

1951. Suicide. New York: The Free Press.

1953. Sociology and Philosophy. New York: The Free Press.

Fagerhaugh, Shizuko Y. and Anselm Strauss. 1977. Politics of Pain Management: Staff-Patient Interaction. San Francisco: University of California.

Garfinkel, Harold. 1967. Studies in Ethnomethodology. Englewood Cliffs: Prentice-Hall.

Giddens, Anthony. 1971. Capitalism and Modern Social Theory. New York: Cambridge University Press.

Ginsberg, Ralph Bertram. 1980. Anomie and Aspirations: A Reinterpretation of Durkheim's Theory. New York: Arno (Dissertations of Sociology).

Goffman, Erving. 1959. The Presentation of Self in Everyday Life. Garden City, New York: Doubleday. 1961. Encounters. Indianapolis: Bobbs-Merrill. 1967. Interaction Ritual: Essays on Face-toFace Behavior. Garden City, New York: Doubleday. 1974. Frame Analysis: An Essay on the Organization of Experience. Cambridge, Mass.: Harvard University Press.

1981. Forms of Talk. Philadelphia: University of Pennsylvania Press.

Hewitt, John P. 1976. Self and Society: A Symbolic Interactionist Social Psychology. Boston: Allyn and Bacon.

Hilbert, Richard A. 1977. “Approaching Reason's Edge: 'Nonsense' as the Final Solution to the Problem of Meaning." Sociological Inquiry 47:25-31.

1980. "Covert Participant Observation: On its

Nature and Practice." Urban Life 9:51-78.

1981. "Toward an Improved Understanding of

'Role'."' Theory and Society 10:207-226.

1982. "Competency Based Teacher Education

Versus the Real World: Some Natural Limitations to Bureaucratic Reform." Urban Education 16:379-398. 1984. "The Acultural Dimensions of Chronic Pain: Flawed Reality Construction and the Problem of Meaning." Social Problems 31:365-378.

Jessor, Richard et al. 1968. Society, Personality, and Deviant Behavior. New York: Holt, Rinehart and Winston.

Johnson, Doyle Paul. 1981. Sociological Theory: Classical Founders and Contemporary Perspectives. New York: John Wiley and Sons.

Johnson, Harry M. 1960. Sociology: A Systematic Introduction. New York: Harcourt, Brace.

Kopel, Steven A. and Hal S. Arkowitz. 1974. "Role 
Playing as a Source of Self-Observation and Behavior Change." Journal of Personality and Social Psychology 29:677-686.

Kotarba, Joseph A. 1977. "The Chronic Pain Experience." Pp. 257-272 in Existential Sociology, edited by Jack D. Douglas and John M. Johnson. New York: Cambridge University Press.

1983. Chronic Pain: Its Social Dimensions. Beverly Hills: Sage.

1983a. "Perceptions of Death, Belief Systems, and the Process of Coping with Chronic Pain." Social Science and Medicine 17:681-689.

Lyman, Stanford M. and Marvin B. Scott. 1970. A Sociology of the Absurd. New York: Appleton-CenturyCrofts.

Manis, Jerome G. and Bernard N. Meltzer, eds. 1967. Symbolic Interactionism: A Reader in Social Psychology. Boston: Allyn and Bacon.

Mannheim, Karl. 1936. Ideology and Utopia. New York: Harcourt, Brace \& World.

Maynard, Douglas W. and Thomas P. Wilson. 1980. "On the Reification of Social Structure." Current Perspectives in Social Theory 1:287-322.

Mead, George H. 1935. Mind, Self and Society. Chicago: The University of Chicago Press.

Merskey, H. and F.G. Spear. 1967. Pain: Psychological and Psychiatric Aspects. London: Bailliere.

Merton, Robert K. 1968. Social Theory and Social Structure. New York: The Free Press.

Meštrović, Stjepan G. 1985. "Anomia and $\operatorname{Sin}$ in Durkheim's Thought', Journal for the Scientific Study of Religion, 24:119-136.

Meštrović, Stjepan G. and Héleǹe M. Brown. f.c. "Durkheim's Concept of Anomie as Déreg̀lement." Forthcoming in Social Problems.

Miles, Robert. 1982. Racism and Migrant Labour. Boston: Routledge \& Kegan Paul.

Mills, C. Wright. 1940. "Situated Actions with Vocabularies of Motive." American Sociological Review 5:904-913.

Nisbet, Robert A. 1974. The Sociology of Emile Durkheim. New York: Oxford University Press.

Pace, J. Blair. 1976. Pain: A Personal Experience. Chicago: Nelson-Hall.

Parsons, Talcott. 1937. The Structure of Social Action. New York: McGraw-Hill. Press. 1951. The Social System. New York: The Free

1968. "Emile Durkheim.” International Encyclopedia of the Social Sciences. New York: The Free Press.

Pollner, Melvin. 1970. On the Foundations of Mundane Reasoning. Unpublished doctoral dissertation. University of California, Santa Barbara.

1974. "Mundane Reasoning." Philosophy of the Social Sciences 4:35-54.

1974a. "Sociological and Common-Sense Models of the Labelling Process." Pp. 27-40 in Ethnomethodology, edited by Roy Turner. Penguin, New York (1974).

1975. “" 'The Very Coinage of Your Brain': The Anatomy of Reality Disjunctures." Philosophy of the Social Sciences 5:411-430.

Psathas, George, ed. 1973. Phenomenological Sociology: Issues and Applications. New York: Wiley.

Rose, Arnold M., ed. 1962. Human Behavior and Social
Processes: An Interactionist Approach. Boston: Houghton Mifflin.

Sapir, Edward. 1949. Selected Writings in Language, Culture, and Personality. Berkeley: University of California.

Sauerbruch, Ferdinand and Hans Wenke. 1963. Pain: Its Meaning and Significance. London: George Allen \& Unwin Ltd.

Schacht, Richard. 1982. "Doubts About Anomie and Anomia'. Pp. 71-91 in Alienation and Anomie Revisited, edited by S. Giora Shoham and Anthony Grahame. Messina, Italy: Sheridan House and Ramot Educational Systems.

Schachter, Stanley and J. Singer. 1962. "Cognitive, Social and Physiological Determinants of Emotional States."' Psychological Review 69:379-399.

Seeman, Melvin. 1982. "A Prolegomenon on Empirical Research Regarding Anomie”. Pp. 121-138 in Alienation and Anomie Revisited, edited by S. Giora Shoham and Anthony Grahame. Messina, Italy: Sheridan House and Ramot Educational Systems.

Shealy, C. Nornan. 1976. The Pain Game. Millbrae, California: Celestial Arts.

Shibutani, Tamotsu. 1961. Society and Personality. Englewood Cliffs, New Jersey: Prentice-Hall.

Shoham, S. Giora and Anthony Grahame, eds. 1982. Alienation and Anomie Revisited. Messina, Italy: Sheridan House and Ramot Educational Systems for the Centre of Sociological, Penal and Penitentiary Research and Studies.

Smith, Dorothy E. 1974. "The Social Construction of Documentary Reality." Sociological Inquiry 44:257-268.

Spector, Malcolm and John I. Kitsuse. 1977. Constructing Social Problems. Menlo Park, California: Cummings.

Srole, Leo. 1956. "Social Integration and Certain Corollaries: An Exploratory Study." American Sociological Review 21:709-716.

Sternbach, Richard A. 1968. Pain: A Psychophysiologic Analysis. New York: Academic Press.

1974. Pain Patients: Traits and Treatments. New York: Academic Press.

Sudnow, David. 1956. "Normal Crimes: Sociological Features of the Penal Code in a Public Defender's Office." Social Problems 12:255-272. 1969. Passing On: The Social Organization of Dying. Englewood Cliffs, New Jersey: Prentice Hall.

Szasz, Thomas S. 1968. "The Psychology of Persistent Pain.' Pp. 42-47 in Proceedings of the International Symposium on Pain, Paris, April 11-13, 1967, edited by A. Soulairac, J. Cahn and J. Charpentier. New York: Academic Press.

Takla, Tendzin and Whitney Pope. 1985. "The Force Imagery in Durkheim."' Sociological Theory 3:74-86.

Thompson, Kenneth. 1982. Emile Durkheim. New York: Tavistock and Ellis Horwood.

Toennies, Ferdinand. 1963. Community and Society. New York: Harper and Row.

Unikel, I.P. and S.I. Chapman. 1978. "The Pain-prone Patient." Pp. 27-33 in Chronic Pain: America's Hidden Epidemic, edited by Steven Brena. New York: Atheneum.

Vygotsky, L.S. 1962. Thought and Language. Edited by Eugenia Haufmann and Gertrude Vakar. Cambridge: MIT Press. 1978. Mind in Societs: The Development of 
Higher Psychological Processes. Cambridge: Harvard University Press.

Whorf, B.L. 1956. Language, Thought and Reality. Cambridge: MIT Press.

Wieder, D. Lawrence. 1974. Language and Social Reality: The Case of Telling the Convict Code. The Hague: Mouton.

. 1974a. "Telling the Code." Pp. 21-26 in Ethnomethodology, edited by Roy Turner. New York: Penguin.

Wilson, Thomas P. 1970. "Conceptions of Interaction and Forms of Sociological Explanation." American Sociological Review 35:697-710.

Zborowski, Mark. 1969. People in Pain. San Francisco: Jossey-Bass.

Zimmerman, Don H. 1970. “The Practicalities of Rule
Use." Pp. 221-238 in Understanding Everyday Life, edited by Jack Douglas. Chicago: Aldine.

1974. "Fact as a Practical Accomplishment." Pp. 128-143 in Ethnomethodology, edited by Roy Turner. New York: Penguin.

1976. "A Reply to Professor Coser." The American Sociologist 11:4-13.

Zimmerman, Don H. and Melvin Pollner. 1970. "The Everyday World as a Phenomenon." Pp. 80-103 in Understanding Everyday Life, edited by Jack Douglas. Chicago: Aldine.

Zimmerman, Don H. and D. Lawrence Wieder. 1970. "Ethnomethodology and the Problem of Order: Comment on Denzin." Pp. 285-295 in Understanding Everyday Life, edited by Jack Douglas. Chicago: Aldine. 